\title{
28 Research Square

\section{Validity and Reliability of Persian Version of the 12- Item Expectations Regarding Aging Survey Iranian Older Adults Population during COVID-19 Pandemic.}

\section{Hamid Sharif Nia}

Mazandaran University of Medical Sciences Faculty of Nursing and Midwifery

\section{Long She}

Taylor's University Taylor's Business School

\section{Sotheeswari somasundram}

Taylor's University Taylor's Business School

\section{Fatemeh khoshnavay fomani}

Tehran University of Medical Sciences School of Nursing and Midwifery

\section{Omolhoda kaveh}

Mazandaran University of Medical Sciences Faculty of Nursing and Midwifery

lida Hosseini ( $\nabla$ l.hosseini69@gmail.com )

Iran University of Medical Sciences https://orcid.org/0000-0001-7635-1710

\section{Research}

Keywords: Psychometrics, validity, reliability, Expectations Regarding Aging

Posted Date: March 11th, 2021

DOI: https://doi.org/10.21203/rs.3.rs-254589/v1

License: (c) (1) This work is licensed under a Creative Commons Attribution 4.0 International License.

Read Full License 


\section{Abstract}

Background: The current pandemic has classified older people into the most vulnerable category. Prior to the pandemic, they led active social lives, but are now cautioned to adopt more precautionary and preventive behaviors. Older people are advised to change their lifestyle given the challenges and expectations regarding aging. Therefore, the present study is designed to assess the construct validity and reliability of the Persian version of the 12-Item Expectations Regarding Aging Survey among older adult Iranian population during COVID-19 pandemic.

Methods: The Persian version of this scale was developed using translation and revision in current study. The construct validity was assessed through Exploratory Factor Analysis (EFA) and Confirmatory Factor Analysis (CFA). Also, the reliability was assessed through through its internal consistency (Cronbach's alpha and McDonald's omega), composite reliability (CR), and maximal reliability (MaxR). The data compiled online was based on a sample of 400 older adults aged above 65 years.

Results: The results of the study indicate that the Persian version of this scale comprises three factors with 11 items (Factor 1: Physical Health; Factor 2: Mental Health; Factor 3: Cognitive Function) that explaining $65.764 \%$ of the total variance. The CFA results, after reviewing the model modification indices, shows the revised three factors model fits the data well with excellent internal consistency and reliability.

Conclusion: The finding indicates that the Persian Version of ERA is reliable and valid. It can be used for aging, educational, and clinic research, to develop and evaluate on suitable intervention to enhance the quality of life among Iranian aging population.

\section{Introduction}

With the onset of Covid 19 disease, the World Health Organization (WHO) has identified quarantine and social isolation as one of the safest ways to control and combat the disease. However, the quarantining a large segment of society will not be without the much dreaded psychological, social and economic effects (1). As a result, older people with active social life are probably experiencing major changes in their normal routine of life, leading to feelings of isolation, loneliness, or low mood (2).

Aging is a critical process of life where physical and mental needs are considered social necessity, and close attention on health-promoting behaviors is essential (3). As part of the aging process, older people would experience change in personality and behaviour, with incidences of loneliness and depression reported as common problems among the elderly $(4,5)$. Studies indicate that loneliness is a painful and nettlesome feeling for older people $(6,7)$, with possibility of multiple negative physical and mental health concerns (8). Needless to say, loneliness and depressions an existing concern among older people is exacerbated during the pandemic. Studies highlight that concerns regarding COVID-19 are higher among older (9), expressing higher vulnerability which impacts their overall attitude to aging (10). The concerns expressed by the elderly is likely justified as the fatality rate of COVID-19 is higher among older compared 
to younger adults. The health concern is connected to the level of expectations regarding aging, hence the importance of addressing this concern among the elderly (11).

Aging expectations (ERA) are beliefs that people have about their level of physical and cognitive health with age (12). The concept of "successful" aging as an alternative to "usual" aging was first mooted by Rowe and Kahn (1997) focusing on importance of health promotion and disease prevention. The proposition was for the elderly to play an active role in their health to enjoy full life as much as possible while maintaining full function (13).

Studies show that there is a positive relationship between attitude and tendency to participate in healthpromoting behaviors such as physical activity, stress management, interpersonal relations, increased longevity and a better quality of life in older adults(14-20). Correspondingly, negative expectations were associated with lower ability to engage in physical activity, accepting a more sedentary lifestyle, a higher likelihood of experiencing acute medical events, negative health outcome, cognitive decline, and emotional responses to stress (21-24) and feelings of loneliness (25).

The importance of expectation in achieving and maintaining a high level of physical and mental function was explored by Sarkisian et al (2002) with a 38- item survey to measure expectations regarding aging (ERA-38) in the USA. The scale incorporated items of general health, cognitive function, mental health, functional independence, sexual function, pain, sleep, fatigue, urinary incontinence and appearance. Higher scores on the ERA-38 expressed an increased attainment of high physical and mental functioning with aging (12). It was interesting to note that functional status and the psychosocial components of health, such as depressive symptoms, social functioning, emotional well-being, and biological and cultural status have a more significant impact on perceptions compared to others aspect (26). It was also noted that older adults' age expectations differed across race/ethnic groups (27).

The limitations of ERA-38, large number of items and the time required for completion, prompted the development of a shorter version, ERA-12. The 12-Item Expectations Regarding Aging Survey support three 4-item sub-scales (expectations about physical health, expectations about mental health, and expectations about cognitive function). The revised instrument, in contrast to ERA-38, does not attempt to show positive or negative conditions (28).

Since the risks of hospitalization or mortality resulted COVID-19 are higher in older adults than in young adults, the use of preventive approach in this group is more emphasized. An approach which is relatable to their view of aging and expectation regarding aging. The attitude adopted by older adults with concerns about COVID-19 can be seen from two perspectives. Firstly, a prescribed isolation may result in older adults feeling lonely or alternatively, Alternatively, the prescribed isolation may result in them feeling safe and more positive (29). If the expectations regarding aging remained relatively stable, a higher resilient was expressed in facing COVID-19 (30).

In justifying the use of ERA-12, it is noted that this instrument showed acceptable validity and reliability when applied to a sample of middle aged Singaporeans, middle aged Koreans and elderly women (31, 
32). The focus of the present study is driven by two important considerations, (1) the increase in the elderly population as a vulnerable group in Iran, and (2) insufficient resources on aging expectations among Iranians which is key in developing informed and effective policies in this area. The present study, therefore, aims to evaluate the construct validity and reliability of Persian version of the 12-Item Expectations Regarding Aging Survey among an Iranian older adult population during COVID-19 pandemic.

\section{Methods}

\section{Design}

A methodological cross-sectional approach is adopted to evaluate the psychometric properties and the feasibility of a Persian version of the "ERA-12". The sample consist of Iranians older adults aged above 65 years, fluent in Persian and residing in Tehran. Additionally, the respondent's criteria to participant in this study include the use of social networks and informed consent is provided to be participated in this study.

\section{Measures}

There were two sections to the questionnaire. First section captures the demographics of the respondents. The following section contains items from the ERA-12 instrument to capture expectations on physical health, mental health, and cognitive function (28) of the elderly in Iran. All items assessing respondents' expectations to aging applies a 4-point Likert scale to be consistent with the original study by Sarkisian et al. (2005).

\section{Procedure}

\section{Translation}

The original ERA-12 instrument developed in English needed to be translated and revised for the Iranian respondents. In order to develop the Persian version of this scale, firstly, a written approval was obtained from Catherine Sarkisian, the developer of the original scale. Upon obtaining the approval, two independent English-Persian translators worked on translating the items. Subsequently, both the translated versions were checked and evaluated by a group of experts (including some of this paper's authors (H.SH and L.H). In the final process, two professional translators proceeded to create a single Persian version of this questionnaire. All of their professional suggestions were included in the translations.

\section{Construct Validity and Reliability Assessment}

In this study, we randomly divided the dataset into two parts to examine the construct validity and reliability. First, the maximum likelihood exploratory factors analysis (EFA) with Varimax rotation was conducted using the first dataset $(n=200)$. The Kaiser-Meyer-Olkin (KMO) measure of sampling 
adequacy test and the Bartlett's test of sphericity were used to ensure the adequacy of the sampling and suitability of the data for conducting factor analysis. Extraction of factor structure was referring the criteria of (1) eigenvalues $>1$; (2) communalities $>.3$, and (2) scree plots (33-35). Next, we conducted the maximum likelihood confirmatory factor analysis (CFA) in accordance with the factor structure obtained from the EFA using second dataset $(n=200)$. The assessment of model fit was based on several fit indices such as Chi-square $\left(\chi^{2}\right)$ test, Chi-square/degree of freedom ratio $\left(\chi^{2} / d f\right)<4$, goodness-of-fit index $(\mathrm{GFI})>.90$, comparative fit index $(\mathrm{CFI})>.90$, incremental fit index $(\mathrm{IFI})>.90$, normed fit index $(\mathrm{NFI})>.90$, Tucker-Lewis index $(\mathrm{TLI})>.90$, relative fit index $(\mathrm{RFI})>.90$, root mean square error of approximation (RMSEA) <.08, and standardized root mean square residual (SRMR) <.09 (36). Moreover, construct validity was assessed through convergent validity and discriminant validity. To achieve convergent validity of the construct, Average Variance Extracted (AVE) should be greater than .5 and composite reliability (CR) should be greater than .7 (37). In this study, we used the Heterotrait-monotrait ratio of correlations (HTMT) in assessing the discriminat validty and all values of the HTMT matrix should be less than $.85(38)$.

The reliability of the Iranian version of ERA-12 was examined through its internal consistency (Cronbach's alpha and McDonald's omega), composite reliability (CR), and maximal reliability (MaxR). Cronbach's alpha and McDonald's omega of higher than .7 are considered as acceptable internal consistency, CR and MaxR should be greater than .7 to demonstrate satisfactory reliability $(37,39)$.

\section{Multivariate Normality and Outliers}

We tested both univariate and multivariate distributions in this study. The outliers, and the values of the skewness and kurtosis were determined and tested for univariate distributions. In terms of multivariate distributions, Mardia's coefficient of multivariate kurtosis was used to check the multivariate normality, the result of Mardia's coefficient was greater than .8 indicating deviation of multivariate normality (40). Also, Mahalanobis distance was used to identify the Multivariate outliers, and multivariate outliers can be identified through a Mahalanobis distance of $p<.001$ (41).

\section{Ethical Considerations}

The Ethics Committee of Mazandaran province, north of Iran approved the Ethical Considerations of this study (Code: IR.MAZUMS.REC.1399.6682). Additionally, we notified all participants regarding the aim and procedures of current study. The participation in this study was voluntary, where informed consent was acquired before participating in this study from all participants. In reporting the findings, the study ensured that the anonymity of the individuals' information was maintained.

\section{Results}

\section{Profiling of Respondents}


The sample of this study consists of $242(60.5 \%)$ males and 158 (39.5\%) females with the mean age of 71.32 (SD \pm 6.09 ) year. Majority of the participants were married $(82.75 \%)$ university graduates $(55.25 \%)$ with good economic status (56.75\%). The details of this results have been shown in Table 1.

\section{Reliability and Validity}

The results of the maximum likelihood EFA with varimax rotation on Persian version of the EARS are shown in Table 2 based on the first dataset $(n=200)$. The results showed that there are three factors are extracted in explaining of $65.764 \%$ of the total variance, containing 11 items. One item was excluded because of low factor loading (<.5). The result of KMO test was .874, and the Bartlett's test of sphericity was significant $(p<.001,995.472, d f=66)$, indicating the adequacy of the sampling and appropriateness of the data to conduct factor analysis. See details in table 2 and figures 1.

Next, we performed maximum likelihood CFA using the second dataset $(n=200)$ to ensure and validate the factor structure extracted from EFA. Figure 2 shows the final measurement model, three sets of measurement errors (between item 7 and 8, item 9 and 10, and item 9 and 12) were free to covary to adjust the initial measurement model in a better fit according to modification indices. The results showed that after reviewing the model modification indices, the revised three factors model fits the data well, as evidenced by goodness-of-fit indices $\left(\chi^{2}(38)=77.272, p<.05, \chi^{2} / d f=2.033, \mathrm{GFI}=.967, \mathrm{CFI}=.981, \mathrm{NFI}=\right.$ $.963, \mathrm{IFI}=.981, \mathrm{RFI}=.947, \mathrm{TLI}=.972, \mathrm{SRMR}=.028, \mathrm{RMSEA}(90 \%$ C.I. $)=.051[.043, .067])$, and factor loadings for all items were more than .6 and significant. Moreover, as presented in Table 3 , the result of Cronbach's alpha (ranged from .788 to .845), McDonald's omega (ranged from .791 to .845), CR (ranged from .772 to .846), and MaxR (ranged from .781 to .863) were all greater than .7 revealing satisfied internal consistency and reliability. Also, the results indicated that AVEs of all three factors were more than .5 and less than their respective $\mathrm{CR}$, demonstrating convergent validity. In terms of discriminant validity, all values in the HTMT matrix analysis were smaller than .85 , indicating discriminant validity established all for constructs (Table 4).

\section{Discussion}

The analysis of psychometric properties of the ERA-12 Persian version carried out on a sample of older adults Iranians based on CFA indicated a three-factor solution of the Expectation Regarding Aging Survey has a good fit after one item was dropped (item 5: I expect that as I get older, I will spend less time with friends and family). The modified model including covariances between three factors (physical health, mental health, and cognitive functions) with total of 11 items showed an improved fit. The findings of the current study demonstrate an acceptable level of reliability, as indicated by good item discrimination scores and Cronbach's alpha values of the ERA-11. An outcome that is supported by previous findings on the three factors solution to the Expectations Regarding Aging questionnaire $(31,42)$. The findings of a systematic review of existing ageism scales showed that among 11 scales included in the study, only the 
Expectations Regarding Aging Questionnaire had adequate ratings on the psychometric properties (43). Despite the mentioned finding, the authors have concluded that none of the available ageism scales have both adequate scop and psychometric validity(43). Considering the three dimensions of ageism that include stereotypes (cognitive component), prejudice (emotional component), and discrimination (behavioral component) (44), the ERA concerns to assess the stereotypes(43).

In justifying the removal of item 5 from the final ERA Persian version, several factors were considered. According to Yao (2020), some factors such as personal values and traits, role models of aging, personal experiences with growing older, and stereotypes about older adults influence on subjective aging. In addition, subjective aging is also influenced by cultural values and social interaction (45) allowing the present study to draws parallels with the cultural values of Iranians, specifically the elder adults' position within the family. Although socio-economic changes have impacted family institution during the last decades, the Iranian families have preserved many of their traditional values, specifically a support system for family members and respect for elder adults. The cultural value system has ensured Iranians maintain a strong relationship with their elderly parents after marriage, including providing care and support for them. Given the contextual sensitivity of subjective age, culture can be considered as the moderator variable in the relationship between views of aging and subjective age (46).

The findings indicate that expectation regarding aging is attributable to physical and mental health, in addition to elder adults' cognitive function that is congruent with the existing knowledge. ERA plays an essential role in implementation of physically active lifestyles for older adults, influencing health conditions, such as physical functions (15). In addition, positive ERA provides social support through network of friends (19), which improves quality of life (47), leading to a positive influence on elderly peoples' mental health (48). Conversely, negative age stereotypes, highlights higher instances of developing psychiatric conditions and impaired coping skills (49). Studies have also noted a deficit in cognitive functioning among negative age stereotypes $(50,51)$.

Our results also demonstrated three pairs of measurement errors. Firstly, between item 7 (as people get older, they worry more) and item 8 (its normal to be depressed when you are old). Next, between item 9 (I expect that as I get older, I will become more forgetful) and item 10 (It's an accepted part of aging to have trouble remembering names). Finally, between item 9 and item 12 (It is impossible to escape the mental slowness that happened with aging). The findings indicate a semantic equivalence between worrying and depressing symptoms among older Iranians. Semantic equivalence is also observed between trouble remembering, being forgetful, and mental slowness. In order to minimize the response burden and increase response rate among older people, shorter questionnaires maybe a possible solution (31). However, further investigations are needed before shortening the next Persian version of the ERA. On the component of age-related health changes among the Iranians, the findings reveal high priority for economic elements such as health insurance and income $(52,53)$. Iranian older people expect that they face by a range of age-related health changes such as memory deficit, to have trouble in remembering names (54), or depressive symptoms $(55,56)$. 


\section{Implication}

Base on evidence, the expectation regarding aging contributes to physical and mental health and cognitive function in elder adults. Therefore, the positive ERA improves older adults' life quality. It is a suitable scale for assessing ERA of older adults and improving target interventions to improve their conditions. It can be used for aging, educational, and clinic research to develop and evaluate on suitable intervention to enhance the quality of life among Iranian aging population.

\section{Study limitations}

This study, however, not without limitation. The sample respondents are from one geographical urban location, Tehran. It is likely, respondents from other regions may have responded differently. As such, a broad generalization of the results to the rural population maybe not be applicable. The efficacy of the Persian ERA can be strengthened by replicating this psychometric testing in other settings and by including comparison with other indicators of aging expectation.

\section{Conclusion}

The present study provides the appropriate Persian version of ERA-11 among Iranian elder adults that can detect and distinct three dimension of ERA in this age group. But the remarkable thing is that this scale can identify the Cognitive Function more powerfully than the Physical and Mental Health in this population.

\section{Declarations}

\section{Ethics approval and consent to participate}

In this study, the ethical points of the Helsinki Declaration were observed, including informing all participants of the objectives and procedures of this study, ensuring the voluntary participation of the study, anonymity of the participants, and obtaining informed consent from all participants.

\section{Consent for publication}

Not applicable

\section{Availability of data and materials}

The datasets generated and analysed during the current study are available from the corresponding author on reasonable request.

\section{Competing interests}

The authors did not have any competing of interest in this work. 


\section{Funding}

Not applicable

\section{Authors' contributions}

HSN and LH designed the study and collected the data and drafted the manuscript. LS analysed the data and contributed to the interpretation of the result and writing the result. FKF and OK contributed to the interpretation of the result and writing the manuscript. All authors read and approved the final manuscript.

\section{Acknowledgements}

We thank all the participants who took part in the study.

\section{Author Details}

${ }^{1}$ Associate Professor, School of Nursing and Midwifery Amol, Mazandaran University of Medical Sciences, Sari, Iran

${ }^{2}$ Faculty of Business and Law, Taylor's University, Subang Jaya, Selangor, Malaysia.

${ }^{3}$ Assistant Professor In Nursing, School Of Nursing And Midwifery, Tehran University Of Medical Science, Tehran, Iran.

${ }^{4}$ Assisstant Professor, Phd Of Nursing, Mazandaran University Of Medical Science, Sari, Iran.

${ }^{5}$ School of Nursing and Midwifery, Iran University of Medical Sciences, Tehran, Iran

\section{References}

1. Khodabakhshi-koolaee A. Living in home quarantine: Analyzing psychological experiences of college students during COVID-19 pandemic. Journal of Military Medicine. 2020;22(2):130-8.

2. Gerst-Emerson K, Jayawardhana J. Loneliness as a public health issue: the impact of loneliness on health care utilization among older adults. American journal of public health. 2015;105(5):1013-9.

3. Abolhasani F, Bastani F. Successful Ageing in the Dimensions of Life Satisfaction and Perception of Ageing in the Iranian Elderly Adults Referring to the Health Center in the West of Tehran, Iran. Iran Journal of Nursing. 2019;31(116):61-74.

4. Beal C. Loneliness in older women: a review of the literature. Issues in mental health nursing. 2006;27(7):795-813.

5. Allan J, Dixon A. Older women's experiences of depression: A hermeneutic phenomenological study. Journal of Psychiatric and Mental Health Nursing. 2009;16(10):865-73. 
6. de Vlaming R, Haveman-Nies A, van't Veer P, de Groot LC. Evaluation design for a complex intervention program targeting loneliness in non-institutionalized elderly Dutch people. BMC public health. 2010;10(1):552.

7. Taube E, Kristensson J, Midlöv P, Holst G, Jakobsson U. Loneliness among older people: Results from the Swedish national study on aging and care-Blekinge. Open Geriatric Medicine Journal. 2013;6(1):1-10.

8. Ong AD, Uchino BN, Wethington E. Loneliness and health in older adults: A mini-review and synthesis. Gerontology. 2016;62(4):443-9.

9. Barber SJ, Kim H. COVID-19 Worries and Behavior Changes in Older and Younger Men and Women. The Journals of Gerontology: Series B. 2020.

10. Ayalon L, Chasteen A, Diehl M, Levy B, Neupert SD, Rothermund K, et al. Aging in times of the COVID19 pandemic: Avoiding ageism and fostering intergenerational solidarity. The Journals of Gerontology: Series B. 2020.

11. Wu Z, McGoogan JM. Characteristics of and important lessons from the coronavirus disease 2019 (COVID-19) outbreak in China: summary of a report of 72314 cases from the Chinese Center for Disease Control and Prevention. Jama. 2020;323(13):1239-42.

12. Sarkisian CA, Hays RD, Berry S, Mangione CM. Development, reliability, and validity of the expectations regarding aging (ERA-38) survey. The Gerontologist. 2002;42(4):534-42.

13. Rowe JW, Kahn RL. Successful aging. The gerontologist. 1997;37(4):433-40.

14. Tuohy D, Cooney A. Older Women's Experiences of Aging and Health: An Interpretive Phenomenological Study. Gerontology and Geriatric Medicine. 2019;5:2333721419834308.

15. Breda Al, Watts AS. Expectations regarding aging, physical activity, and physical function in older adults. Gerontology and Geriatric Medicine. 2017;3:2333721417702350.

16. Kim SH. Older people's expectations regarding ageing, health-promoting behaviour and health status. Journal of Advanced Nursing. 2009;65(1):84-91.

17. Meisner BA, Baker J. An exploratory analysis of aging expectations and health care behavior among aging adults. Psychology and Aging. 2013;28(1):99.

18. Meisner BA, Weir PL, Baker J. The relationship between aging expectations and various modes of physical activity among aging adults. Psychology of Sport and Exercise. 2013;14(4):569-76.

19. Menkin JA, Robles TF, Gruenewald TL, Tanner EK, Seeman TE. Positive expectations regarding aging linked to more new friends in later life. Journals of Gerontology Series B: Psychological Sciences and Social Sciences. 2017;72(5):771-81.

20. Korkmaz Aslan G, Kartal A, Özen Çınar İ, Koştu N. The relationship between attitudes toward aging and health-promoting behaviours in older adults. International journal of nursing practice. 2017;23(6):e12594.

21. Cheng ST, Yip LC, Jim OT, Hui AN. Self-perception of aging and acute medical events in chronically institutionalized middle-aged and older persons with schizophrenia. International journal of geriatric 
psychiatry. 2012;27(9):907-13.

22. Monahan C, Macdonald J, Lytle A, Apriceno M, Levy SR. COVID-19 and ageism: How positive and negative responses impact older adults and society. American Psychologist. 2020.

23. Siebert JS, Braun T, Wahl H-W. Change in attitudes toward aging: Cognitive complaints matter more than objective performance. Psychology and Aging. 2020.

24. Bellingtier JA, Neupert SD. Negative aging attitudes predict greater reactivity to daily stressors in older adults. The Journals of Gerontology: Series B. 2018;73(7):1155-9.

25. Shiovitz-Ezra S, Shemesh J, McDonnell M. Pathways from ageism to loneliness. Contemporary perspectives on ageism: Springer; 2018. p. 131-47.

26. Löckenhoff CE, De Fruyt F, Terracciano A, McCrae RR, De Bolle M, Costa PT, et al. Perceptions of aging across 26 cultures and their culture-level associates. Psychology and aging. 2009;24(4):941.

27. Menkin JA, Guan S-SA, Araiza D, Reyes CE, Trejo L, Choi SE, et al. Racial/ethnic differences in expectations regarding aging among older adults. The Gerontologist. 2017;57(suppl_2):S138-S48.

28. Sarkisian CA, Steers WN, Hays RD, Mangione CM. Development of the 12-Item Expectations Regarding Aging Survey. The Gerontologist. 2005;45(2):240-8.

29. Shahid Z, Kalayanamitra R, McClafferty B, Kepko D, Ramgobin D, Patel R, et al. COVID-19 and older adults: what we know. Journal of the American Geriatrics Society. 2020;68(5):926-9.

30. Whatley MC, Siegel AL, Schwartz ST, Silaj KM, Castel AD. Younger and Older Adults' Mood and Expectations Regarding Aging During COVID-19. Gerontology and Geriatric Medicine. 2020;6:2333721420960259.

31. Joshi VD, Malhotra R, Lim JF, Ostbye T, Wong M. Validity and reliability of the expectations regarding aging (ERA-12) instrument among middle-aged Singaporeans. Ann Acad Med Singapore. 2010;39(2):394-8.

32. Park MH, Kweon Y. Testing the validity and reliability of Korean version of the Expectations Regarding Aging (ERA-12) Instrument among middle-aged and elderly women. Journal of Korean Public Health Nursing. 2014;28(3):460-70.

33. Cattell RB. The Scree Test For The Number Of Factors. Multivariate Behavioral Research. 1966;1(2):245-76.

34. Cattell RB, Jaspers J. A general plasmode (No. 30-10-5-2) for factor analytic exercises and research. Multivariate Behavioral Research Monographs. 1967;67-3:211-.

35. Field A. Discovering statistics using IBM SPSS statistics: Sage; 2013.

36. Sharif Nia H, Pahlevan Sharif S, Koocher GP, Yaghoobzadeh A, Haghdoost AA, Mar Win MT, et al. Psychometric properties of the death anxiety scale-extended among patients with end-stage renal disease. OMEGA-Journal of Death and Dying. 2020;80(3):380-96.

37. Nia HS, Sharif SP, Froelicher ES, Boyle C, Goudarzian AH, Yaghoobzadeh A, et al. Psychometric evaluation of a Persian version of the cardiac depression scale in Iranian patients with acute myocardial infarction. Journal of Nursing Measurement. 2018;26(1):1-15. 
38. Henseler J, Ringle CM, Sarstedt M. A new criterion for assessing discriminant validity in variancebased structural equation modeling. Journal of the Academy of Marketing Science. 2015;43(1):11535.

39. Hair JF, Black WC, Babin BJ, Anderson RE. Multivariat Data Analysis. 7th Editio ed: Pearson Education Limited; 2014.

40. Raoprasert T, Islam SMN. Designing an Efficient Management System: modeling of convergence factors exemplified by the case of Japanese businesses in Thailand: Springer Science \& Business Media.; 2010.

41. Harrington D. Confirmatory factor analysis. New York:: Oxford University Press.; 2009.

42. Cho S-H, Choi M, Lee J, Cho H. Relationship between Expectations Regarding Aging and Physical Activity among Middle Aged Adults in Urban Areas: Based on the Pender's Health Promotion Model. Journal of Korean Academy of Nursing. 2015;45(1).

43. Ayalon L, Dolberg P, Mikulionienè S, Perek-Białas J, Rapolienè G, Stypinska J, et al. A systematic review of existing ageism scales. Ageing research reviews. 2019;54:100919.

44. Iversen TN, Larsen L, Solem PE. A conceptual analysis of ageism. Nordic Psychology. 2009;61(3):422.

45. Yao Jr JJ. A theoretical perspective on aging attributions and expectations: Its role in health behaviors and outcomes. Cogent Psychology. 2020;7(1):1798634.

46. Hess TM, O'Brien EL, Voss P, Kornadt AE, Rothermund K, Fung HH, et al. Context influences on the relationship between views of aging and subjective age: The moderating role of culture and domain of functioning. Psychology and Aging. 2017;32(5):419.

47. Şahin DS, Özer Ö, Yanardağ MZ. Perceived social support, quality of life and satisfaction with life in elderly people. Educational Gerontology. 2019;45(1):69-77.

48. Harandi TF, Taghinasab MM, Nayeri TD. The correlation of social support with mental health: A metaanalysis. Electronic physician. 2017;9(9):5212.

49. Levy BR, Chung PH, Slade MD, Van Ness PH, Pietrzak RH. Active coping shields against negative aging self-stereotypes contributing to psychiatric conditions. Social Science \& Medicine. 2019;228:25-9.

50. Brubaker MS, Naveh-Benjamin M. The effects of stereotype threat on the associative memory deficit of older adults: American Psychological Association; 2018.

51. Barber SJ, Hamel K, Ketcham C, Lui K, Taylor-Ketcham N. The effects of stereotype threat on older adults' walking performance as a function of task difficulty and resource evaluations. Psychology and aging. 2020;35(2):250.

52. Kiarsipour N, Borhani F, Esmaeili R, Zayeri F. The correlation of aging perceptions and life satisfaction in Iranian older adults. Annals of Tropical Medicine and Public Health. 2017;10(4):861.

53. Zanjari N, Sharifian Sani M, Hosseini Chavoshi M, Rafiey H, Mohammadi Shahboulaghi F. Perceptions of successful ageing among Iranian elders: insights from a qualitative study. The 
International Journal of Aging and Human Development. 2016;83(4):381-401.

54. Ebadi A, Ebtekar F, Parizad N, Afkhamzadeh A, Dalvand S, Gheshlagh RG. Psychometric Properties Of The Persian Version Of The Memory Impact Questionnaire In Older Adults. Neuropsychiatric Disease and Treatment. 2019;15:3197.

55. Momeni P, Wettergren L, Tessma M, Maddah S, Emami A. Factors of importance for self-reported mental health and depressive symptoms among ages 60-75 in urban Iran and Sweden. Scandinavian journal of caring sciences. 2011;25(4):696-705.

56. Faramarzi M, Cheraghi M, Zamani M, Kheirkhah F, Bijani A, Hosseini SR. Gender-specific predictors of depressive symptoms among community elderly. Journal of Research in Health Sciences. 2017;17(2):377.

\section{Tables}

Table 1 Demographic Profile

\begin{tabular}{|c|c|c|c|}
\hline Variables & $n(\%)$ & Variables & $n(\%)$ \\
\hline Gender & & Number of Child & \\
\hline Male & $242(60.50)$ & None & $44(11.00)$ \\
\hline Female & $158(39.50)$ & One & $42(10.50)$ \\
\hline Marital Status & & Two & $132(33.00)$ \\
\hline Single & $29(7.25)$ & Three & $90(22.50)$ \\
\hline Married & 331 (82.75) & Four and more & $92(23.00)$ \\
\hline Divorced & $13(3.20)$ & Employment Status & \\
\hline Widow & $27(6.80)$ & Unemployed & $24(6.00)$ \\
\hline Education Level & & Manual worker & $7(1.75)$ \\
\hline Illiterate & $18(4.50)$ & Retired & $172(43.00)$ \\
\hline Elementary & $51(12.75)$ & Employed & $98(24.50)$ \\
\hline Middle School & $30(7.50)$ & Housewife & $56(14.00)$ \\
\hline High School & $80(20.00)$ & Free & $43(10.75)$ \\
\hline University & $221(55.25)$ & Lifestyle & \\
\hline Economic Condition & & Along & $44(11.00)$ \\
\hline Worse & $44(11.00)$ & With wife & $74(18.50)$ \\
\hline Medium & $129(32.25)$ & With wife and children & $256(64.00)$ \\
\hline Good & $227(56.75)$ & With relatives & $26(6.50)$ \\
\hline \multicolumn{4}{|l|}{ Living address } \\
\hline Personal home & $385(96.25)$ & & \\
\hline Children home & $14(3.5)$ & & \\
\hline Nursing home & $1(0.25)$ & & \\
\hline
\end{tabular}

Table 2 The result of EFA on the three factors Iranian version of ERA $(\mathrm{N}=200)$ 


\begin{tabular}{|c|c|c|c|c|c|}
\hline Factor & Items & $\begin{array}{l}\text { Factor } \\
\text { loading }\end{array}$ & h2 & $\lambda$ & $\begin{array}{c}\% \\
\text { Variance }\end{array}$ \\
\hline \multirow[t]{4}{*}{$\begin{array}{c}\text { Physical } \\
\text { Health }\end{array}$} & $\begin{array}{l}\text { 2.The human body is like a car: when it gets old, it gets } \\
\text { worn out. }\end{array}$ & .737 & .622 & 2.162 & 19.656 \\
\hline & $\begin{array}{l}\text { 3. Having more aches and pains is an accepted part of } \\
\text { aging. }\end{array}$ & .628 & .549 & & \\
\hline & $\begin{array}{l}\text { 4.Every year that people age, their energy levels go down } \\
\text { a little more. }\end{array}$ & .588 & .478 & & \\
\hline & $\begin{array}{l}\text { 1.When people get older, they need to lower their } \\
\text { expectations of how healthy they can be. }\end{array}$ & .547 & .374 & & \\
\hline \multirow{3}{*}{$\begin{array}{l}\text { Mental } \\
\text { Health }\end{array}$} & 8.It's normal to be depressed when you are old. & .657 & .668 & 1.054 & 9.581 \\
\hline & 7. As people get older they worry more. & .601 & .517 & & \\
\hline & $\begin{array}{l}\text { 6.Being lonely is just something that happens when } \\
\text { people get old. }\end{array}$ & .512 & .518 & & \\
\hline \multirow[t]{4}{*}{$\begin{array}{l}\text { Cognitive } \\
\text { Function }\end{array}$} & $\begin{array}{l}\text { 11. Forgetfulness is a natural occurrence just from } \\
\text { growing old. }\end{array}$ & .840 & .843 & 4.018 & 36.527 \\
\hline & $\begin{array}{l}\text { 10. It's an accepted of aging to have trouble } \\
\text { remembering names. }\end{array}$ & .629 & .550 & & \\
\hline & $\begin{array}{l}\text { 12.It is impossible to escape the mental slowness that } \\
\text { happens with aging. }\end{array}$ & .599 & .589 & & \\
\hline & $\begin{array}{l}\text { 9. I expect that as I get older I will become more } \\
\text { forgetful. }\end{array}$ & .552 & .452 & & \\
\hline
\end{tabular}

Table 3 Internal consistency, construct reliability, and convergent validity of Iranian version of ERA $(N=200)$

\begin{tabular}{lccccc}
\hline Factors & Cronbach's alpha & McDonald's omega & CR & MaxR & AVE \\
\hline Physical Health & .788 & .791 & .800 & .809 & .501 \\
\hline Mental Health & .789 & .793 & .772 & .781 & .531 \\
\hline Cognitive Function & .845 & .845 & .846 & .863 & .581 \\
\hline
\end{tabular}

Table 4 Discriminant validity assessment using HTMT matrix Factor Physical Health Mental Health Cognitive Function

\section{Physical Health}

Mental Health $\quad 0.780$

\begin{tabular}{lll}
\hline Cognitive Function & 0.599 & 0.830
\end{tabular}






Figure 1. Parallel Analysis Scree Plot

Figure 1

Parallel Analysis Scree Plot 




Figure 2

Confirmatory Factor Analysis On the Results Obtained from EFA ( $N=200)$ 